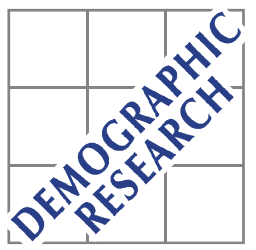

Demographic Research a free, expedited, online journal of peer-reviewed research and commentary in the population sciences published by the Max Planck Institute for Demographic Research Konrad-Zuse Str. 1, D-18057 Rostock · GERMANY www.demographic-research.org

DEMOGRAPHIC RESEARCH

VOLUME 27, ARTICLE 4, PAGES 85-120

PUBLISHED 13 JULY 2012

http://www.demographic-research.org/Volumes/Vol27/4/

DOI: 10.4054/DemRes.2012.27.4

Research Article

\title{
Regional family norms and child care by grandparents in Europe
}

\section{Maaike Jappens}

\section{Jan Van Bavel}

This publication is part of the proposed Special Collection "Intergenerational family ties in Europe: Multiple linkages between individuals, families and social contexts", edited by Pearl Dykstra.

(C) 2011 Maaike Jappens \& Jan Van Bavel.

This open-access work is published under the terms of the Creative Commons Attribution NonCommercial License 2.0 Germany, which permits use, reproduction \& distribution in any medium for non-commercial purposes, provided the original author(s) and source are given credit. See http:// creativecommons.org/licenses/by-nc/2.0/de/ 


\section{Table of Contents}

1 Introduction $\quad 86$

$2 \quad$ Grandparents and child care in Europe $\quad 87$

2.1 Characteristics of grandparents, parents and children $\quad 88$

$\begin{array}{ll}2.2 & \text { International variation }\end{array}$

$\begin{array}{lll}2.3 & \text { Formal child care provision } & 91\end{array}$

3 Regional family practices and norms $\quad 93$

$4 \quad$ Hypotheses, data, and methods $\quad 95$

4.1 Hypotheses 95

4.2 Data and methods 96

4.3 Dependent variable: grandparents as the main source of child care 98

4.4 Explanatory variables on the regional level 99

4.5 Explanatory variable on the country level 105

4.6 Explanatory variables on the individual level 105

$\begin{array}{lll}5 & \text { Results } & 107\end{array}$

$\begin{array}{lll}6 & \text { Conclusions } & 111\end{array}$

$7 \quad$ Acknowledgements 113

References 114 


\title{
Regional family norms and child care by grandparents in Europe
}

\author{
Maaike Jappens ${ }^{1}$ \\ Jan Van Bavel ${ }^{2}$
}

\begin{abstract}

\section{BACKGROUND}

Child care is widely considered a key issue in confronting demographic change in Europe today, given its centrality in the labour market participation of parents, and of mothers in particular. There are considerable international differences in child care practices throughout Europe, and earlier comparative research has indicated that structural factors do not suffice to explain them.
\end{abstract}

\section{OBJECTIVE}

We investigate whether or not, next to structural differences, cultural factors also play a role in European international variations in child care practices, and more specifically the use of grandparental child care.

\section{METHODS}

Using the second wave of the European Social Survey, this paper scores subnational regions of 23 European countries on different dimensions of family norms and practices. We construct regional indicators and use them in a multilevel analysis of the use of grandparents as the main source of child care by European mothers.

\section{RESULTS}

Results show that European mothers' reliance on grandparental child care is influenced by individual characteristics and the supply of formal child care, but also by the normative climate in the region they live in. Irrespective of the attitudes individually held, we find that mothers in more conservative regions are more inclined to use grandparents as the main source of child care instead of formal alternatives.

\section{CONCLUSIONS}

European patterns of child care use are not only subject to structural factors as the supply of formal care provisions for children. Preferences and attitudes prevalent in the regions in which young parents live form an important part of the picture too.

\footnotetext{
${ }^{1}$ Interface Demography, Vrije Universiteit Brussel.

${ }^{2}$ Centre for Sociological Research, Family and Population Studies, University of Leuven. Interface Demography, Vrije Universiteit Brussel
} 


\section{Introduction}

In 2005, the European Commission published the Green Paper Confronting demographic change: a new solidarity between the generations about the way European and national policy makers could and should respond to population ageing in the $21^{\text {st }}$ century. One of the core recommendations of the Commission was to increase employment rates. In particular, the labour market activity of women was put forward as an essential priority (European Commission 2005). As a matter of fact, the European Council already aimed at raising female employment rates by setting out the Lisbon Strategy in 2000 (High Level Group chaired by Wim Kok 2004).

The European policy objective of increasing the labour market participation of women and especially of young mothers has to deal with the following two circumstances. First, Europe was and is characterized by regional diversity of beliefs, norms, and attitudes, as well as practices in family life and gender roles. In some regions, there exists considerable normative resistance to the idea that a mother with young children could - let alone should - go out to work. According to the logic of this belief, an increase in the employment rate of mothers would imply that more women would postpone or forgo the transition to motherhood, to make room for activity in the labour market. At the same time, the birth rate is already very low in this type of region and the European Commission would prefer to see a slight increase in the birth rates (European Commission 2005). Second, unless one would expect fathers to stay home to care for the children, boosting the labour market participation of mothers implies that provisions for child care are available. In some regions, however, there exists distrust of providing child care for young children in formal facilities such as nurseries (Wheelock and Jones 2002; Van Bavel 2004; Arpino, Pronzato, and Tavares 2010). Typically, these regions have hardly invested in such facilities, and many working parents living there have to rely on informal alternatives - mainly their own parents - to care for their children. Various studies confirm that a considerable share of European grandparents does indeed help their children by providing child care for the grandchildren. The importance of grandparental child care varies greatly across Europe, and this variation is in turn strongly associated with variations in the availability of public child care facilities (Wheelock and Jones 2002; Lewis, Campbell, and Huerta 2008; Smith Koslowski 2009; Hank and Buber 2009; Igel and Szydlik2011; Settles et al. 2010).

Hence, culture-bound family practices and child care are two important elements which policy makers should take into account when attempting to increase the labour force participation of women. This article focuses on child care provided by grandparents, and investigates how the use of this type of child care can be explained by regional family practices and norms. Particularly, we study which factors make certain mothers count on grandparents as their main source of child care, while others turn to 
formal care facilities. Former research about grandparents and child care shows that, in addition to individual characteristics of grandparents, parents and children, contextual factors such as the availability of formal alternatives also play a role. There exist few studies of the role of cultural differences in grandparental child care, even if there are clear indications that they matter too. We will investigate whether the use of grandparental child care by European mothers is mainly connected to mothers' own situation and attitudes towards family and gender roles, or is rather the regional family practices and norms that prevail. The chief source of data for this article is the second round of the European Social Survey (ESS2). Using this source of data allows us to contribute to filling another gap in the existing literature: in spite of the sociological, political, and demographic interest of Eastern Europe, there has hardly been any attention to grandparental child care in post-communist countries. Based on ESS2-data, we involve Western, as well as Eastern Europe in our analyses.

\section{Grandparents and child care in Europe}

Grandparental child care can come in several forms. In exceptional circumstances, custodial grandparents may take the role of surrogate parents. Even if this is the exception, it is happening more and more often (e.g. Dunne and Kettler 2007; Leder, Nicholson Grindstead, and Torres 2007; Erbert and Alemá 2008). Far more commonplace is the arrangement of grandparents providing regular informal child care for their grandchildren when parents are away from home for work or other activities. It is this form of grandparental child care that is the focus of this paper.

Many grandparents provide some kind of care for their grandchildren when the parents are unable to do so, and most do so unpaid. This may reflect the willingness of grandparents to participate in the lives of their grandchildren and to help their children. The help of grandparents can be crucial for working mothers during years when both work and the care of the children are very demanding. For grandparents it can be important to support their daughters and give them chances to improve their labour market position, chances that many grandmothers themselves did not have (Tobío et al. 2010).

Grandparental child care can also reflect the preference among parents for this type of care. Some parents prefer to rely on grandparents for child care because they perceive them as the most trustworthy, providing a safe and emotionally nurturing environment that benefits their children. Other parents choose grandparental child care because it is the most convenient. Using grandparental child care may also represent the only affordable or available option (Wheelock and Jones 2002; Brandis 2003; Guzman 2004; Fergusson, Maughan, and Golding 2008). 
Data from the 2004 Survey of Health, Ageing and Retirement in Europe show that 49 percent of Western European grandfathers and 58 percent of grandmothers with grandchildren aged 15 or younger provide some kind of care for a grandchild. Around 30 percent do so almost weekly or more often (Hank and Buber 2009). A European aged 50 years and over spends on average 0,5 hours per day looking after grandchildren, while she or he devotes on average 1,5 hours working in the market and 0,3 hours helping relatives, friends or neighbours (Croda and Gonzalez-Chapela 2005). Grandparents are the second most significant group of non-maternal child care givers, second after the male partners (Fergusson, Maughan, and Golding 2008). In their research about instrumental support in families, Knijn and Liefbroer (2006) found that in the Netherlands, family members help each other most with child minding. More than half of the adult children said that their parents had helped them caring for their children during the last months before the interview. This is higher than the proportion of people who exchanged any other kind of support.

From earlier research we know that the prevalence and intensity of grandparental child care depends on various factors: the availability and willingness of the grandparents, the needs and preferences of parents and their children, but also contextual factors. These sets of factors are discussed in the next sections.

\subsection{Characteristics of grandparents, parents and children}

Grandparental child care is a gendered activity. Evidence consistently shows that grandmothers are more likely to be engaged in it than grandfathers, particularly in case of intensive child care (Fuller-Thomson and Minkler 2001; Brandis 2003; Guzman 2004; Fokkema, Ter Bekke, and Dykstra 2008; Hank and Buber 2009; Igel and Szydlik 2011; Danielsbacka 2011; Ghysels 2011). Younger grandparents tend to provide more child care than older grandparents (Fuller-Thomson and Minkler 2001; Hank and Buber 2009). Health limitations can deter grandparents from providing grandchild care (Croda and Gonzalez-Chapela 2005; Hank and Buber 2009; Igel and Szydlik 2011). As to grandparents' employment status some researchers found that a higher percentage of employed grandparents at least once in a while provide child care than those who are not employed or retired (Guzman 2004). But when it comes to regular child care, working grandparents are clearly less likely to be involved (Sannen and Hedebouw 2002; Croda and Gonzalez-Chapela 2005; Gray 2005; Hank and Buber 2009). Also grandparents' partner status seems to affect variation in grandchild care: lone grandparents, certainly grandfathers, are less likely to care for their grandchildren than those living with a partner (Sannen and Hedebouw 2002; Knijn and Liefbroer 2006; 
Fokkema, Ter Bekke, and Dykstra 2008; Hank and Buber 2009; Igel and Szydlik 2011; Ghysels 2011).

As to parental characteristics, gender again matters: maternal grandparents are more often involved in child care than paternal grandparents (Hank and Buber 2009; Tobío et al. 2010; Danielsbacka 2011; Ghysels 2011). Age is also a factor: younger parents are more likely to use grandparental child care than older ones (Vandell et al. 2003; Fergusson, Maughan, and Golding 2008; Hank and Buber 2009). The probability that grandparents provide child care is generally higher if the grandchild's mother is employed (Hank and Buber 2009; Ghysels 2011), and if her average working week is longer than usual (Gray 2005). Working nights, weekends and other nonstandard hours is also associated with higher involvement of grandparents in child care, as this may make grandparental child care one of the only available options (Vandell et al. 2003; Guzman 2004). Lone parents seem to be more likely to be supported with child care by grandparents than parents living with a partner (Gray 2005; Fergusson, Maughan, and Golding 2008; Hank and Buber 2009; Ghysels 2011). Reliance on grandparental help may also be a function of the social class of the parents. As formal child care may be too expensive for some parents, grandparents are more likely to help parents with financial problems (Gray 2005; Fergusson, Maughan, and Golding 2008; Smith Koslowski 2009). More highly educated mothers are less likely to receive help with child care from a grandparent. This may be because better educated mothers are more geographically mobile and have experienced greater independence, or because grandparents perceive them as more able to find alternatives (Fergusson, Maughan, and Golding 2008).

The literature shows that some characteristics of children are also related to the probability that they are cared for by grandparents. Grandparents are most likely to provide child care for preschool-aged children, except for toddlers. The older the grandchildren, the less likely grandparental care (Guzman 2004; Hank and Buber 2009; Igel and Szydlik 2011). First-born or only children more often receive grandparental child care than second or subsequent children, as caring for more than one child becomes a more difficult task for grandparents (Fergusson, Maughan and Golding 2008; Igel and Szydlik 2011; Ghysels 2011).

Residential proximity also plays an important role. Grandparents who live nearby are more likely to provide child care than those who live further away, particularly if regular care is considered (Sannen and Hedebouw 2002; Guzman 2004; Hank and Buber 2009; Igel and Szydlik 2011; Ghysels 2011). If grandparent, parent and child live in the same household, the likelihood of grandparental child care increases substantially (Vandell et al. 2003). 


\subsection{International variation}

The proportion of grandparents providing child care varies greatly between European countries. Using findings from the 2004 Survey of Health, Ageing and Retirement, Hank and Buber (2009) investigated cross-national variations in grandparental child care for ten continental West European countries. Their analysis is restricted to nonresidential grandparents aged 50 or older with at least one grandchild under the age of 16. In Spain, Italy and Switzerland, they observed the lowest shares of grandparents caring for grandchildren: about half of the grandmothers and 40 percent of grandfathers. The highest prevalence of care was found in Sweden, France, The Netherlands and Denmark, particularly in the latter two countries, where more than 65 percent of grandmothers and 60 percent of grandfathers provide child care. Focusing on the intensity of provided grandchild care, however, yields a completely different story. In Sweden, Denmark and France, around 20 percent of grandparents providing grandchild care does so 'almost weekly or more often'. The share of Mediterranean grandparents looking after grandchildren almost weekly or more is twice as high (Hank and Buber 2009).

These inter-country differences were still found after controlling for several of the characteristics of grandparents, parents and children mentioned above. The authors suggest the existence of three groups of countries. In the first group, containing Austria, Germany and Switzerland, grandparents exhibit an average propensity to provide both "any" and "regular" child care. In the second group, grandparents are most likely to provide any child care at all, but they are least likely to look after grandchildren on a regular basis. The Scandinavian countries, the Netherlands, and France are in this group. The third group consists of the Mediterranean countries. Here, grandparents are less likely to provide child care, but those who do provide child care are more likely to do so regularly (Hank and Buber 2009). Post-communist countries in Central and Eastern Europe were not included in this research.

Lewis, Campbell, and Huerta (2008) use ESS2 data to explore the ways in which parents in couple families reconcile employment with child care in 13 Western European member states. As a part of this, they calculated the percentage of working mothers with children under six years old that use grandparents as the main type of child care. Greece, Belgium and Austria are countries where the biggest proportions of working mothers use grandparents as the main child care provider (all more than 40 percent). Here, there are even more mothers using grandparents as their main child care provider than mothers using formal child care provisions. The Netherlands, Portugal, Germany, Ireland, Great Britain, Spain and Finland take an average position, with between 34 and 24 percent of working mothers usually having the grandparents looking after the children. In Sweden, France and Denmark, grandparents are less used as the main child care source (Lewis, Campbell, and Huerta 2008). This study too did not 
include post-communist Eastern European countries, even though this is possible using ESS2-data.

For Eastern European countries, research on the topic of child care, or on family issues generally, is rather limited (Robila 2004; Szelewa and Polakowski 2008). Under communist government, the state had a powerful impact on and control over the family, and to encourage women to take part in the labour force, public and affordable child care services were provided in most countries. The fall of communism reduced the involvement of the state in family life, and brought a revival of patriarchal attitudes towards families and the male-breadwinner model. Many public child care services were closed down and state expenditures on child care were reduced, however with considerable differences between post-communist countries (Kocourková 2002; Robila 2004; Szelewa and Polakowski 2008). In spite of their sociological, political, and demographic interest, these countries in Central and Eastern Europe have not been included in earlier comparative research on child care by grandparents in Europe.

\subsection{Formal child care provision}

Research has clearly shown that the availability of formal sources of child care plays an important role in patterns of grandchild care: where there are more formal alternatives, parents rely less on help from grandparents (Attias-Donfut, Ogg, and Wolff 2005a; Gray 2005; Lewis, Campbell, and Huerta 2008; Hank and Buber 2009; Smith Koslowski 2009; Igel and Szydlik 2011; Settles et al. 2010). There exists considerable variation in family policy and child care programs across Europe. Besides the common growth trend, publicly provided child care services are at very different stages of development in European countries (European Monitoring Centre on Change 2006; Plantenga and Remery 2009; Settles et al. 2010; Saraceno 2011).

First of all, public investment in child care varies greatly by country. According to OECD estimates, Denmark and Iceland had the highest investment in early child care services including pre-primary education (as percent of GDP) in 2005. France, Sweden and Finland were following. Belgium and Norway were taking an intermediate position, while other countries invested only half or less than Denmark and Iceland (OECD 2008a).

Also formal child care coverage rates for children aged less than three years show considerable country differences. Figure 1 presents child care coverage rates around the year 2003, as included in the database on intergenerational policy indicators provided by the EU-FP7 project Multilinks (Keck, Hessel, and Saraceno 2009). The coverage rate is defined as the number of places in public or publicly subsidized child care facilities as a share of the number of children aged zero to two years. Belgium, Denmark and 
Sweden stand out with coverage rates above 50 percent, France and Norway follow with rates around 40 percent. Coverage rates in Eastern and Southern European countries such as Poland, Hungary, Greece, Bulgaria and the Czech Republic, on the other hand, amount to less than ten percent. Enrolment rates in pre-school education programs are usually much higher, with less variation between countries (OECD 2008b; Keck, Hessel, and Saraceno 2009).

Figure 1: Child care coverage rates in public or publicly subsidized facilities for children under three years, around 2003

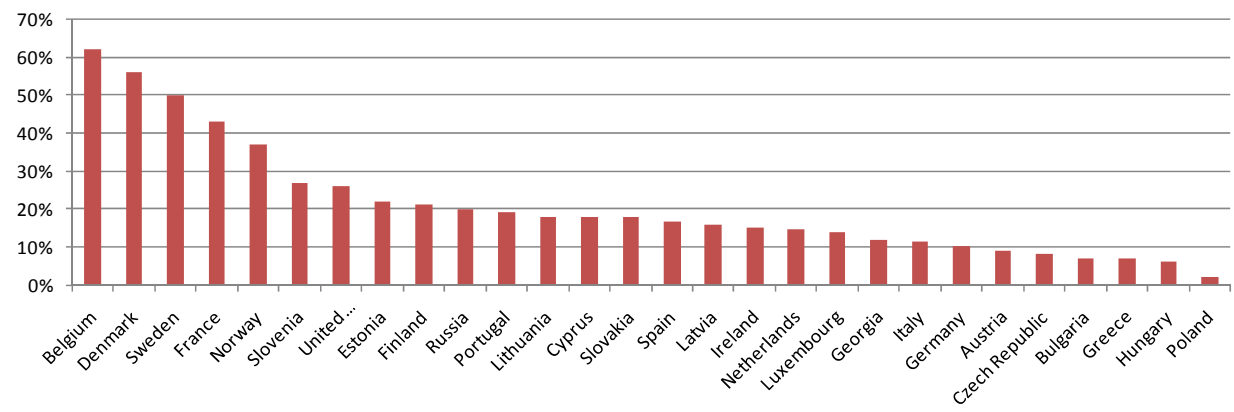

Source: Multilinks database on intergenerational policy indicators (Keck, Hessel, and Saraceno 2009)

Where formal child care is abundant, maternal employment is fostered and the role of grandparents in child care can be limited to special circumstances, for example in case of illness or working overtime (Hank and Buber 2009; Settles et al. 2010). Combining data from SHARE and OECD, Igel and Szydlik (2010) found that in Western European countries in which the state provides considerable child care facilities, more grandparents do indeed support their children sporadically with child care. In contrast, when the state provides only weak support, fewer grandparents engage in grandchild care, but those who do look after grandchildren are more likely to do so regularly (Igel and Zdydlik 2010). A lack of formal child care hinders the labour market participation of parents, typically of mothers. In such circumstances, mothers who still want or need to go out to work will have to rely more intensely on informal child care, in most cases provided by grandparents (Hank and Buber 2009; Settles et al. 2010).

Next to the supply of formal child care and the labour market participation of young mothers, other structural factors have an influence on the importance of grandparental child care. These include parental working hours and the participation of 
grandparents in the labour market (Attias-Donfut, Ogg, and Wolff 2005a; Gray 2005; Lewis, Campbell, and Huerta 2008; Hank and Buber 2009; Smith Koslowksi 2009). Taken together, structural factors still do not seem to suffice to explain the European differences in the use of grandparents as child care providers. Therefore, beliefs about care, gender roles and family obligations and the strength of family networks and solidarity are expected to play an important role too (Lewis, Campbell, and Huerta 2008; Saraceno 2011). This is what we want to verify empirically in this paper.

\section{Regional family practices and norms}

Although European families face common demographic changes, family life differs considerably from region to region. In social demography, one of the most common typologies to summarize the differences that have been observed in European family life is the north-south division. Reher (1998) identifies 'persistent contrasts' between familialistic cultures in the south of Europe and individualistic cultures in the north. In Southern or Mediterranean European countries family ties are argued to be strong, while Northern European countries would be characterized by rather weak family ties. "There are regions where traditionally the family group has had priority over the individual, and others where the individual and individual values have had priority over everything else" (Reher 1998: 203). This contrast is deeply rooted in cultural and historical differences, and Reher sees no indication that it will fade away. Despite the many changes the future will bring, he is convinced that a clear distinction between strong and weak family-systems will survive.

In making the distinction between familialistic and individualistic Europe, Reher focuses on coresidence: in familialistic countries, it happens far more often that parents and adult children and possible grandchildren are living under the same roof than in individualistic countries (Reher 1998). Yet, coresidence is just one particular type of family support between older parents and adult children. Also, when they are not living together, parents and children may have strong ties, have frequent contacts, and support each other in various ways (see Dykstra and Fokkema 2011 for a typology). Considerable amounts of help in everyday housework and care are exchanged between parents and children, also when living in separate households, and financial transfers take place both up and down the generational line. Here too, there exists considerable variation across Europe (Bettio and Plantenga 2004; Tomassini et al. 2004; AttiasDonfut, Ogg, and Wolff 2005a; 2005b; Kohli, Künemund, and Lüdicke 2005; Albertini, Kohli, and Vogel 2007; Hank 2007; Kohli and Albertini 2007; Wolff and Attias-Donfut 2007; Kalmijn and Saraceno 2008; Brandt, Haberkern, and Szydlik 2009; Igel et al. 2009; Schenk, Dykstra, and Maas 2009; Dykstra and Fokkema 2011). The variation in 
family practices and patterns of solidarity between family members is not just shaped by micro-level factors such as the needs and preferences of family members. Economic and demographic circumstances, social policies and public services, as well as cultural climates all play a role, and these macro-level factors influencing regional variations in family practices are inextricably intertwined (Albertini, Kohli, and Vogel 2007; Heady and Kohli 2010; Kohli and Heady 2010; Dykstra 2012).

Next to patterns of intergenerational family support and living arrangements, norms and attitudes towards the roles of men and women in the family and obligations to support family members vary between different regions of Europe. There are, for example, substantial differences in individual attitudes towards the gender division of work and care, manifested in different degrees of labour market participation of women. Broadly seen, people in Southern and Eastern European countries hold more traditional family values and have a higher sense of duty towards one's family than in Western and Nordic Europe (Daatland and Herlofson 2003; Georgas et al. 2004; Voicu 2004; Fokkema, Ter Bekke, and Dykstra 2008). While traditional values do change over time, just like actual practices, some patterns persist over prolonged periods of time (Reher 1998; Inglehart and Baker 2000).

In this article, we include measures of two family practices mentioned above: patterns of coresidence and intergenerational exchange of support. Next to that, we also include indicators for norms about men, women and the family. We do not stick to a simplistic division between Northern and Southern Europe: although this division is easy to make, it does not always seem to summarize the European reality very well (Dykstra and Fokkema 2011). First, very often it is hard to classify some of the countries in one of the categories (Kalmijn and Saraceno 2008). Ireland, as an example, in several respects resembles more Mediterranean Europe than other Northern European countries (Reher 1998; Georgas et al. 2004). Second, a North-South division seems to be having a hard time handling the post-communist countries in Central and Eastern Europe. These countries have witnessed rapid and dramatic demographic changes during the past decades, are undergoing divergent socioeconomic and political developments, and have welfare systems that differ from those in the rest of Europe (Robila 2004; Fokkema, Ter Bekke, and Dykstra 2008; Inglot 2008). Moreover, family practices and value patterns do not only differ between countries or groups of countries; there also exist considerable differences between regions within European countries. These regional differences have historical roots too (Todd 1990; Beugelsdijk, Van Schaik and Arts 2006; Duranton, Rodríguez-Pose, and Sandall 2007; Kalmijn and Uunk 2007). Differences between regions within a country may even be bigger than differences between countries. This is the case in Spain and Italy, for example, where family life in the north of the country differs radically from that in the more 
conservative and familialistic southern part (Viazzo 2003; Kohli, Künemund, and Lüdicke 2005; Santarelli and Cottone 2009; Micheli 2012).

Instead of developing a typology, we account for the regional heterogeneity by scoring regions on different family practices and norms. To this end, we create a series of four variables on the level of regions within European countries, all measured in the first decade of this century, and we control for the economic situation of a region by adding the gross domestic product per capita. This allows to account for variation within national states, as well as to observe similar patterns in neighboring regions from different countries. We do not only do so for Western Europe, we also include Eastern European regions. We use the regional indicators in a multilevel analysis to investigate whether the family practices and the norms prevailing in a region affect the use of grandparental child care, in addition to individual needs and attitudes and the supply of formal child care.

\section{Hypotheses, data, and methods}

Many young parents actually piece together a 'jigsaw' of child care when they are not able to care for their children themselves, using a mix of formal and informal child care. The latter is mostly provided by the grandparents. In this article, we are interested in the extent to which parents rely on grandparents as the main source of child care for their children, meaning they turn to the child's grandparents first, or more intensely, than to other, mainly formal alternatives of child care.

\subsection{Hypotheses}

Based on the results of our literature review, we expect the probability that grandparents provide the main source of child care to be higher if mothers are younger, in paid work and achieved a lower level of education. Also if mothers are divorced or single, we expect the probability that they mainly rely on grandparents for the care of their children to be higher. If grandparents - especially grandfathers - are single and if mothers have more children that need child care, we expect the likelihood that they mainly use grandparental care to be lower.

Besides these characteristics of mothers, their parents and their children, former studies point to the importance of the availability of formal child care. Where more formal child care is available, we expect that the probability that mothers mainly rely on grandparents to care for their children is lower. Where formal child care services are 
scarce, on the other hand, we expect mothers will be more inclined to mainly use the help of grandparents.

Next to this important structural factor, our main hypothesis is that the normative context also plays a role in the child care use of European mothers. We predict that mothers living in a region where traditional gender and family norms prevail are more likely to mainly use grandparental child care. We have the same expectation for mothers living in a region where it is common that parents live in the same household as their adult children, and possibly grandchildren. The indicators for these regional level factors are introduced in section 4.4 and will be employed in multilevel regression analysis.

\subsection{Data and methods}

We use data from the second round of the European Social Survey (ESS2), with fieldwork carried out in 2004 and 2005. In a rotating module, the ESS2 questioned respondents about attitudes towards gender and family roles, the use of child care and intergenerational exchange of support and care (ESS Central Coordinating Team 2010). In addition to the ESS2, we use GDP data from Eurostat and statistics about formal child care provision from the Multilinks database on intergenerational policy indicators (Keck, Hessel, and Saraceno 2009).

We use multilevel logistic regression analysis to investigate whether mothers mainly use grandparental child care for their children. Our random intercepts models contain explanatory variables on three levels: the individual level, the level of the region within a country, and the level of the country mothers live in. Note that, in the following, "grandparents" always refers to the parents or parents-in-law of the respondents, while "children" refers to the children of the respondents. When we talk about "mothers", we mean the respondents included in our analysis themselves.

The European Social Survey contains information on regions within the countries surveyed, but it is not straightforward to combine this information with EU regional statistics because the ESS2 regional classification differs from the standard regional classification used by Eurostat, the EU statistical office. For our purposes, we first had to harmonize the ESS2 regional classification with Eurostat's NUTS system. NUTS is the Nomenclature of Territorial Units for Statistics, a coherent and standardized system for referencing subnational regions within European countries, created and regulated by the European Union. NUTS is a hierarchical system, with three levels of NUTS defined. We work on the NUTS 1 level, which is the level of major NUTS regions. NUTS 1 regions count minimum 3 and maximum 7 million inhabitants. Large countries such as Germany and France are divided into 16 or 9 NUTS 1 regions. For countries with a 
small population size such as Ireland and Luxembourg, the NUTS 1 level corresponds to the entire country (Różańska-Putek et al. 2009). Our choice to work on the first NUTS level was constrained as the ESS does not contain the information required to construct NUTS 2 or NUTS 3 regions for all countries. Moreover, applying a higher NUTS level would leave some regions without observations for our analysis.

Twenty-six countries participated in the second round of the ESS: Austria, Belgium, Czech Republic, Denmark, Estonia, Finland, France, Germany, Greece, Hungary, Iceland, Ireland, Italy, Luxembourg, Netherlands, Norway, Poland, Portugal, Slovakia, Slovenia, Spain, Sweden, Switzerland, Turkey, UK and Ukraine. Data from Italy are not included in the main ESS2 dataset, because the rotating modules were administered as split ballot there (ESS Central Coordinating Team 2010). This also means that only half of the respondents were asked the questions in the rotating module about family, work and wellbeing, but data for Italy were added to the dataset and included into the following analyses. Data from Turkey, Ukraine and the United Kingdom, however, were dropped from the analysis. Ukraine is not part of Eurostat's NUTS classification. Turkey has a large number of NUTS regions due to the large population size, but as the total ESS2 sample size is not bigger than in other countries, the number of respondents in some regions is too small. Moreover, reliable and comparable data on child care are hard to find for these two countries. The United Kingdom was dropped from the analyses because data on education level were omitted from the international file due to insufficient questions on the topic (ESS Central Coordinating Team 2010).

Therefore, the following analyses are based on ESS2 data from 23 countries (see Table 1) and 74 NUTS 1 regions. To adjust for the differences in sample design between countries, cases have been weighted by the design weight provided by ESS. Population weights were not applied, since we are more interested in the differences between countries and regions than in estimating an overall pan-European effect. The analysis of child care by grandparents is restricted to women aged 20 to 54 who have at least one child younger than 13 years living in their household. Table 1 shows the unweighted numbers of mothers in this age group that were included in our analyses, per country. On the NUTS 1 regional level, the sample varies between minimum one and maximum 189 mothers per region. 
Table 1: Countries included in the analysis and number of mothers aged 20-54 with children 0-12 in the household

\begin{tabular}{lrlr}
\hline Country & $\mathbf{N}$ & Country & $\mathbf{N}$ \\
\hline Austria & 148 & Ireland & 189 \\
Belgium & 128 & Iceland & 64 \\
Switzerland & 144 & Italy & 46 \\
Czech Republic & 149 & Luxembourg & 90 \\
Germany & 166 & Netherlands & 142 \\
Denmark & 145 & Norway & 178 \\
Estonia & 109 & Poland & 106 \\
Spain & 64 & Portugal & 170 \\
Finland & 127 & Sweden & 130 \\
France & 147 & Slovenia & 93 \\
Greece & 107 & Slovakia & 77 \\
Hungary & 96 & & 2815 \\
\end{tabular}

\subsection{Dependent variable: grandparents as the main source of child care}

Respondents with children aged 12 or under living with them were asked about the main type of child care they used for the youngest child: "Thinking about the youngest child in the household, I would like to ask you about his/her usual child care, not counting lessons in school. By child care I mean care carried out by anyone other than yourself or your current husband/wife/partner. What is the main type of child care that the youngest child receives?" Respondents could select one type of child care, one of them being the child's grandparent(s). So, our dependent variable does not inquire whether or not mothers ever use grandparental child care, nor the intensity of this type of child care. It is possible that, for example, some children mainly go to paid nursery, but are also cared for by the grandparents one day a week. It is important to keep this in mind: in this article, we only look at the type of child care mothers use most. We created a dummy indicating whether or not grandparents were selected as the main source of child care for the youngest child in the household, as opposed to formal or other informal care. Respondents who answered that their youngest child could manage alone at home or that no child care was needed were left out of the analysis, so our analysis addresses only women with an explicit demand for child care. 


\subsection{Explanatory variables on the regional level}

Based on ESS2, we constructed an indicator of conservative norms about family life and three indicators for family practices as explanatory variables on the NUTS 1 level: the percentage of older people co-residing with children, the percentage of older parents providing care or support with housework to adult children outside the household, and the percentage of older parents receiving care or support from children outside the household. We also control for the economic situation of the region by including the gross domestic product.

\section{Family norms}

The ESS2 presented five statements about gendered family roles to respondents, who had to indicate whether they agreed strongly, agreed, neither agreed nor disagreed, disagreed, or disagreed strongly. These statements were: 1) "A women should be prepared to cut down on her paid work for the sake of her family", 2) "Men should take as much responsibility as women for the home and children", 3) "When jobs are scarce, men should have more right to a job than women", 4) "When there are children in the home, parents should stay together even if they do not get along", and 5) "A person's family ought to be his or her main priority in life".

These items were used to construct a measure of conservative family norms. Based on an exploratory principal components analysis and further examination of the items, item 2 and item 5 were dropped from the scale. These items correlate only weakly with the other three, so their loadings are low. Moreover, less than 5 percent of respondents disagreed with statement 2 , probably because 'taking responsibility for the home and children' can be interpreted in different ways, including men taking the breadwinner role. For item 5, less than 4 percent of respondents disagree that a person's family ought to be his or her main priority in life, irrespective of the attitudes towards the other items. This resulted in a scale of conservative family norms with three items. Table 2 shows the principal component loadings for the three indicators. This principal component analysis was carried out with all respondents in our ESS2 database, irrespective of age or gender.

First, principal component scores were calculated for all respondents, as an individual-level covariate. Second, to construct a measure of the normative climate in European regions, only the scores of respondents aged 55 or older, men and women, were averaged per NUTS 1 region. This restricted age span is chosen to avoid having our indices of regional family culture directly reflect the opinions of the people whose child care will be modelled as a function of these indices. So, deliberately, our measures of family culture reflect the attitudes held by the older part of the population while our model is about the child care used by the younger part of the population. The average 
scores for conservative family culture per region are displayed in Map 1. The higher the component scores, the more conservative the normative climate.

\section{Table 2: Loadings for items in principal component 'conservative family} norms'

\begin{tabular}{lc}
\hline Items & Component loading \\
\hline A woman should be prepared to cut down on her paid work for the sake & 0.757 \\
of her family. & \\
When jobs are scarce, men should have more right to a job than women. & 0.807 \\
When there are children in the home, parents should stay together even & 0.693 \\
if they don't get along. & \\
\hline
\end{tabular}

Extraction method: principal component analysis, Cronbach's $\alpha=0.619$

The total number of observations that we used to construct the regional variables is 15170 , but differs considerably between regions, ranging from 6 to 1162, with a mean of 205 respondents aged 55 and older per NUTS 1 region. This implies that the reliability of our indices of family culture varies greatly by region, which will undermine our statistical power to find their effects, if any, on the dependent variable. For this reason, due to the noise introduced by small numbers of observations in some regions, our estimates of the effect of regional family culture on grandparental care need to be considered as conservative estimates. If we find effects, we are presumably dealing with underestimations of the real effects (Woodhouse et al. 1996). Still, in order to double check the robustness of the findings we will present below, we have refitted our models with only a subset of the countries. More specifically, in our robustness check, we have excluded the countries with the smallest numbers of respondents in some of their NUTS 1 regions (namely Spain, Italy, Germany and France) and then redone our analysis on this restricted dataset. These results (not included in this paper but available on request from the authors) are very similar to the ones presented below.

More conservative family norms are, broadly summarized, mainly found in Southern and Eastern Europe, but it is clear that there are substantial differences between regions, even between regions within countries. In Belgium for example, the northern region of Flanders scores markedly lower on conservative family norms than Wallonia in the south. Also in Spain, typically considered as one of the countries where more conservative family values prevail, people of 55 and older in Catalonia clearly hold less conservative family norms than in Andalusia. 
Map 1: Average scores for conservative family norms

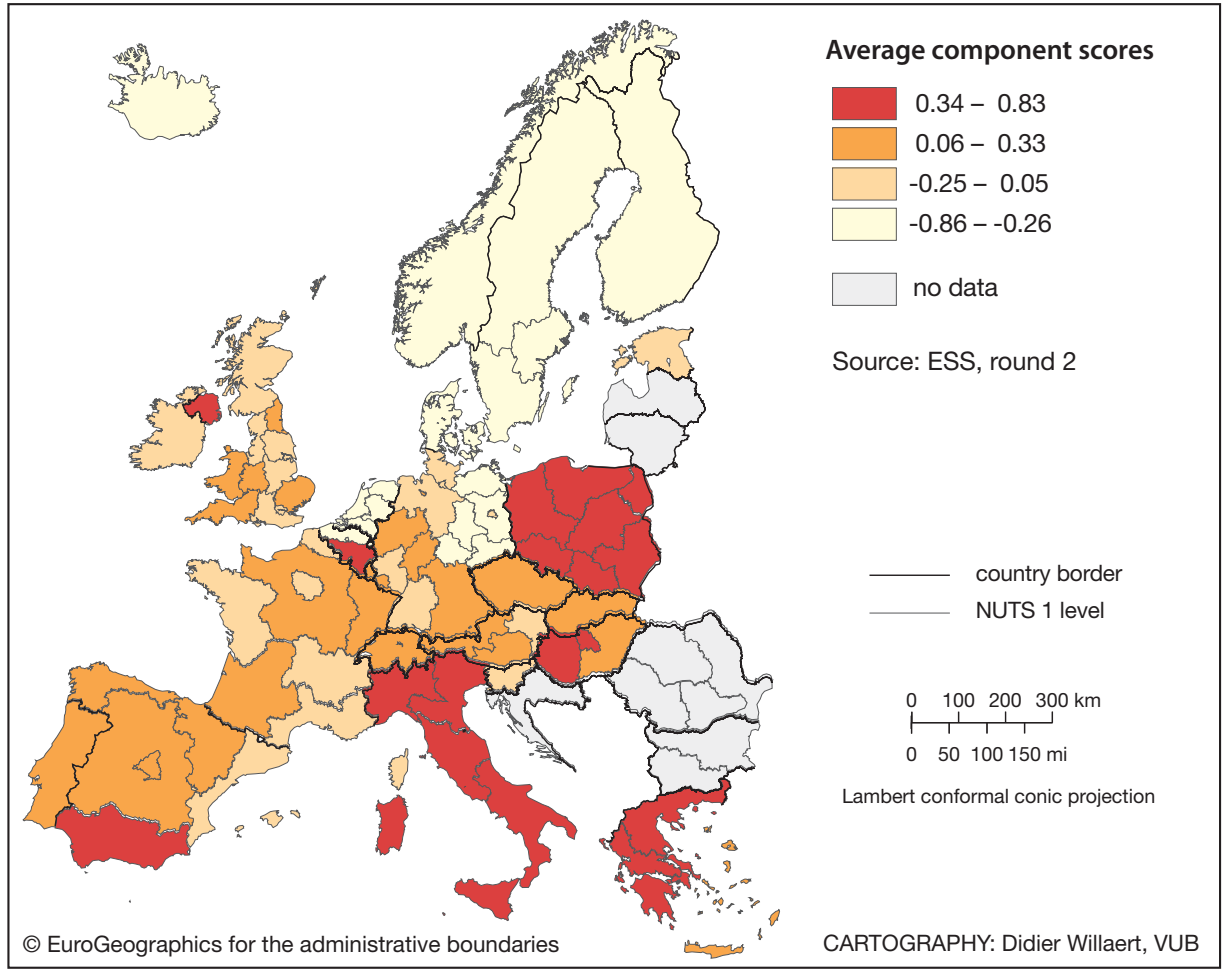

Coresidence of older parents with their children

The ESS household grid registers the relationship respondents have with their household members, one of them being 'son/daughter, including step, adopted, foster, child of partner'. The percentage of respondents aged 55 years and older in the region, living with at least one son or daughter in the same household, was aggregated as an indicator on the NUTS 1 level. Map 2 shows the variation of coresidence between older parents and adult children across European regions.

As expected, Western Europe is marked by a clear difference between Mediterranean and Northern Europe. In most Northern European regions, coresidence with children encompasses less than 15 percent of respondents aged 55 or older, while in Spain, Italy and Greece more than 33 percent of older respondents live with offspring. The situation in Ireland is similar to that of Southern Europe. Also in Eastern 
European regions, coresidence between elderly parents and children is more common. Although a lot of variation in this indicator is situated between country-borders, this resume neglects numerous intra-country differences in coresidence of older parents and children.

Map 2: $\quad$ Respondents aged 55 or older living with at least one of their children in the household, \% per NUTS 1 region

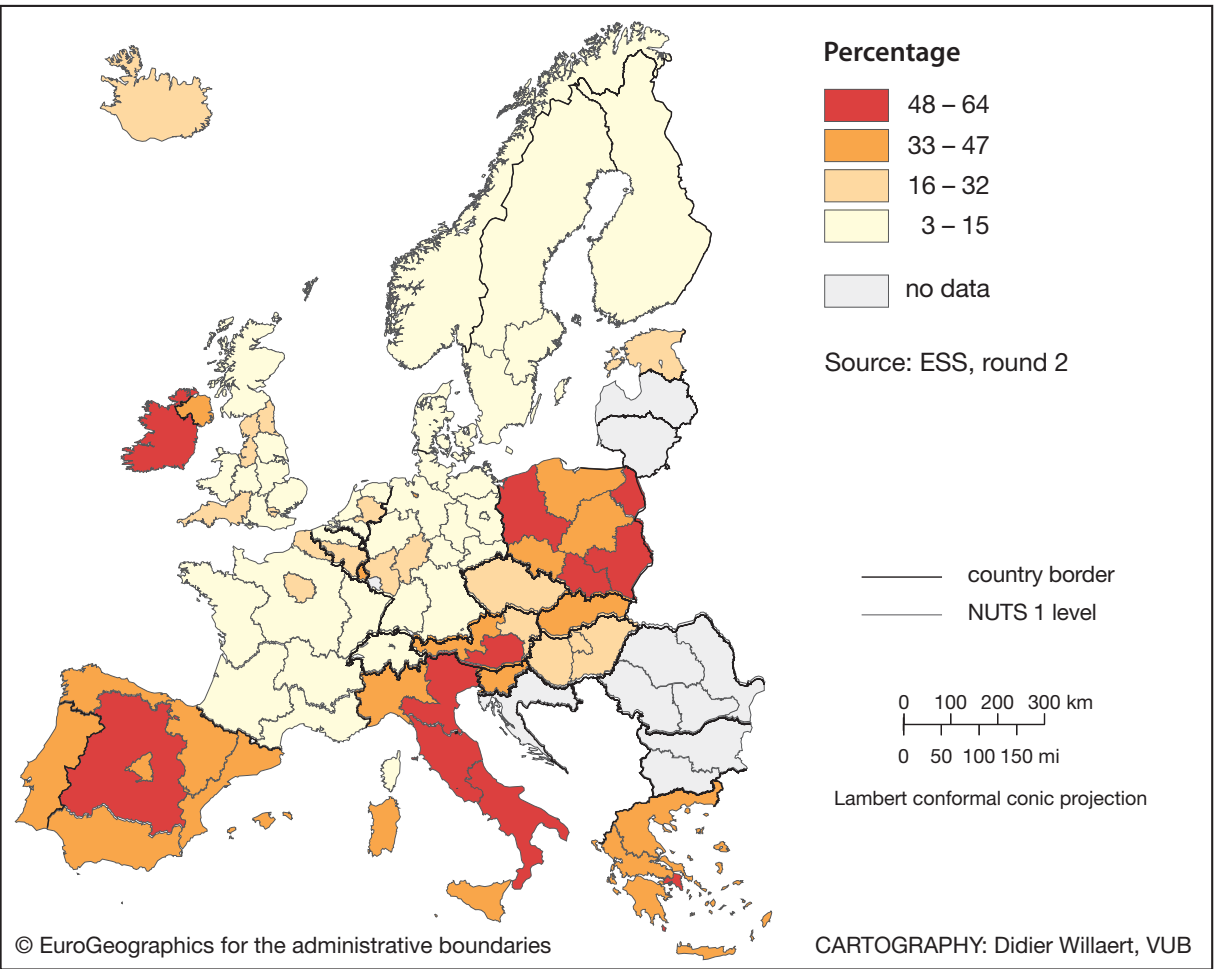

Intergenerational exchange of care and support in housework

ESS2 asked respondents about support in everyday housework and about care they provide for, and receive from, adult children or grandchildren not living in the same household. Possible answers were 1) a lot of support, 2) some support and 3) no support. Categories 1 and 2 were combined to one category indicating that at least some support was exchanged. Only respondents aged 55 or older having at least one child 
aged 18 or older living outside their household were taken into account. Aggregated variables were constructed on the NUTS 1 level, representing the percentage exchanging support with their adult children living separately. Map 3 presents the percentage of respondents aged 55 or older with adult children outside the household providing support for adult children, Map 4 presents the percentage receiving support from children.

Map 3: $\quad$ Respondents aged 55 or older with children aged 18 or older outside the household providing support in everyday housework or care to adult children living apart, \% per NUTS 1 region

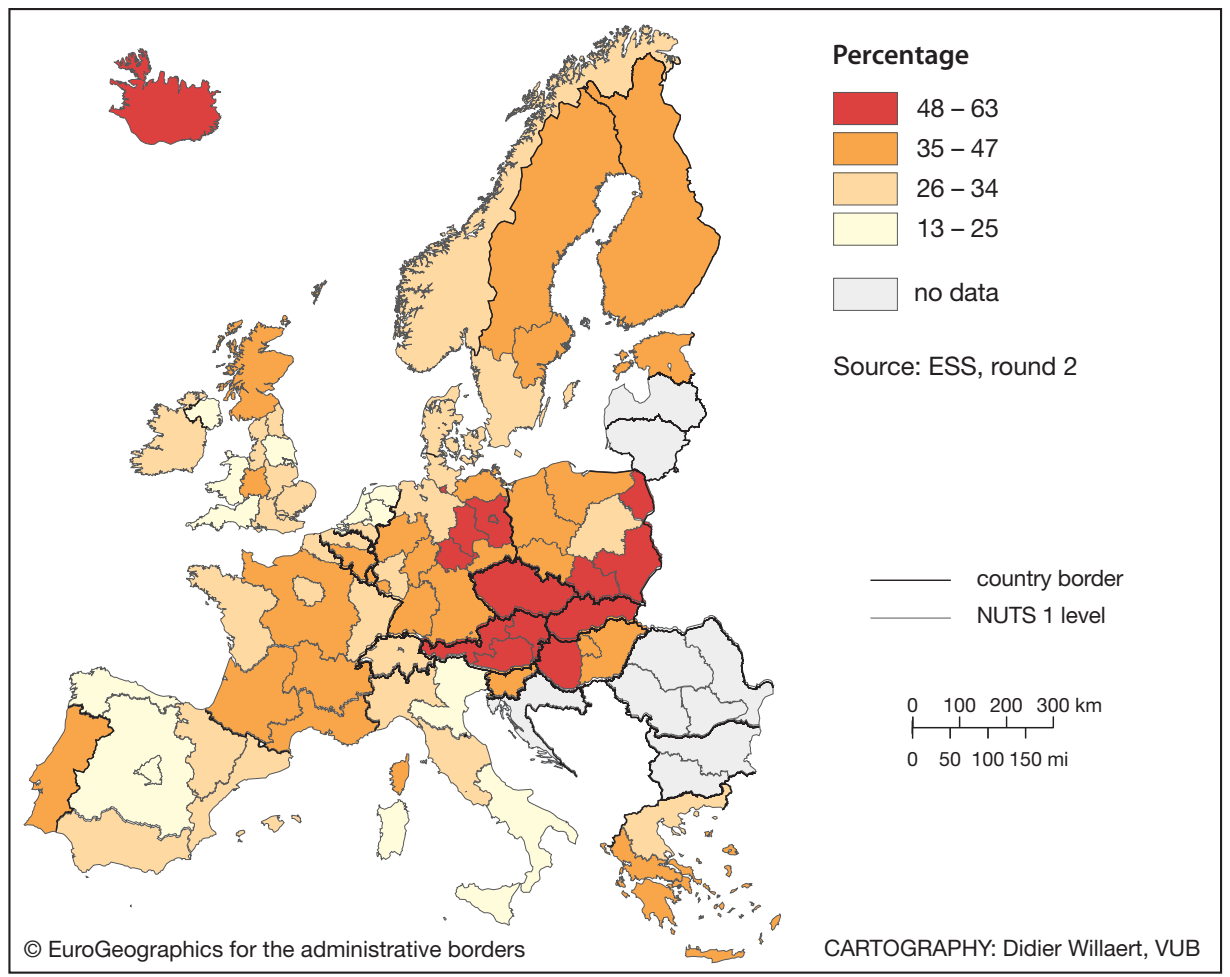

Comparison of both maps shows that, roughly summarized, the regions where more parents provide help with housework or care to adult children outside the household, are also the regions where more parents receive this kind of support from 
offspring. Mostly Eastern European regions exhibit high levels of support exchange, although with substantive differences within countries. The lowest percentages of people exchanging everyday support with children living outside the household are, perhaps surprisingly, located in Mediterranean Europe. In these Southern European regions coresidence of elderly parents and children is more common and may function as a main form of intergenerational support.

Map 4: $\quad$ Respondents aged 55 or older with children aged 18 or older outside the household receiving support in everyday housework or care from adult children living apart, \% per NUTS 1 region

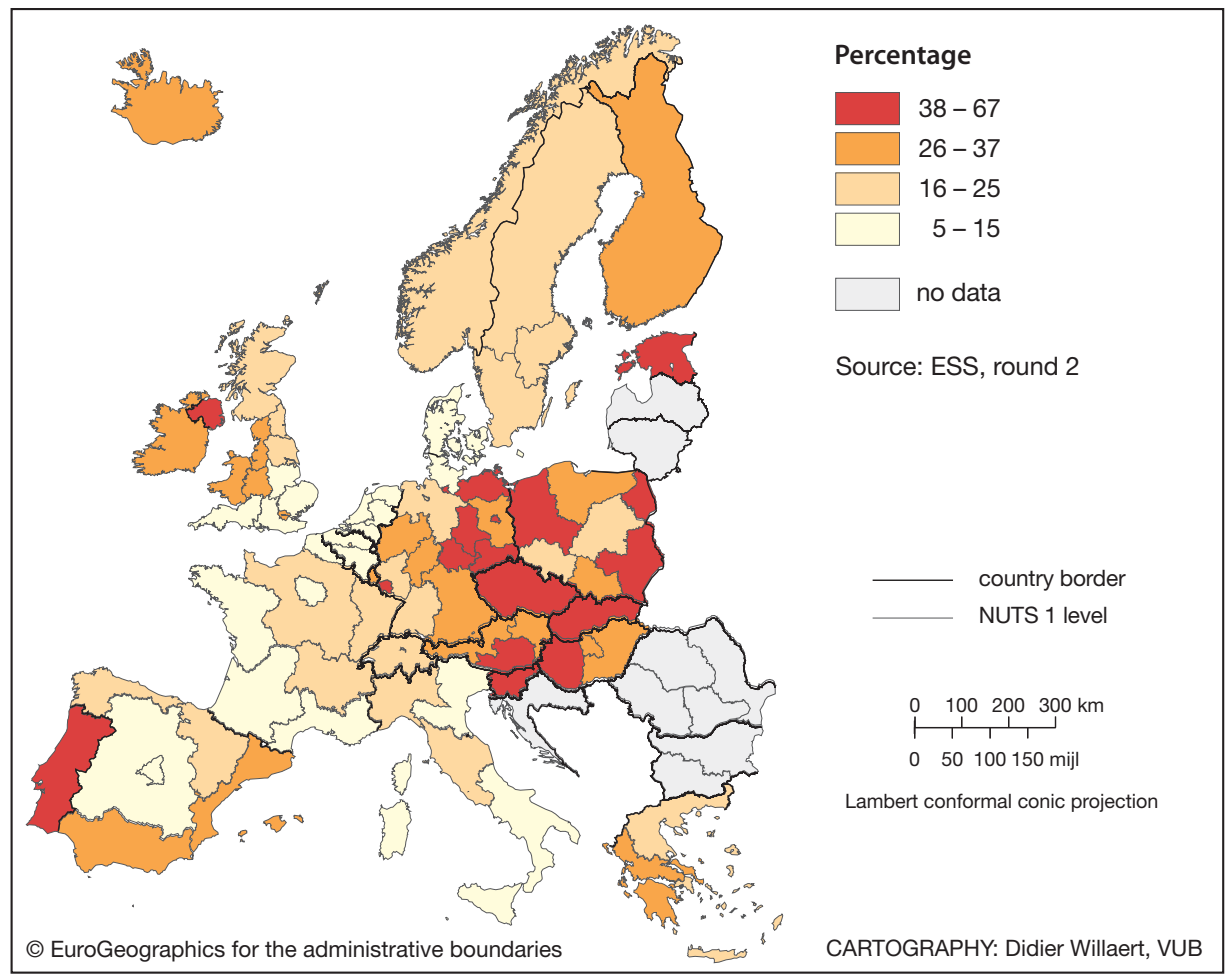

This finding is in line with findings from Albertini, Kohli, and Vogel (2007), based on SHARE-data. They suggest that "coresidence is the Southern European way of transferring resources from parents to children and vice versa. This is the norm, and 
when it happens that an elderly parent remains alone he/she is less likely to give or receive help than an elderly parent in the Continental or Nordic countries" (Albertini, Kohli, and Vogel 2007: 326). Most Central and Eastern European regions show yet a different pattern of intergenerational family support. Like in Mediterranean regions, a substantive share of people aged 55 or older live in the household with children. But also when parents and children do not live together, many of them exchange support in housework and care.

\section{Gross domestic product per capita}

Southern and especially Eastern European regions and countries are usually less wealthy than Northern and Western European countries. Therefore, to anticipate the argument that the hypothesized effect of regional family practices could be spurious, we also control for the economic situation of the regions in our analysis. We include the gross domestic product at market prices for the year 2005, as provided by Eurostat (2010). To assure the comparability between regions, GDP is expressed in Purchasing Power Standard per inhabitant.

\subsection{Explanatory variable on the country level}

From former research we know that the availability of formal care facilities plays a major role in the use of grandparental child care. Data on formal child care are not available on the regional level, only on the level of European countries. We use formal child care coverage rates from the database on intergenerational policy indicators provided by the EU-FP7 project Multilinks. This database on intergenerational policies includes a set of indicators and describes social policies and legal frameworks in 29 European countries, all around the year 2004 (Keck, Hessel, and Saraceno 2009). We include the child care coverage rate for children under 3 in the analyses, representing the number of places in public or publicly subsidized child care facilities as a share of the number of children aged 0 up to 2 years. Switzerland and Iceland are not represented in the Multilinks-database. Data on child care coverage for Iceland (year 2005) were derived from the OECD family database (2010), data for Switzerland (year 2003) from Immervoll and Barber (2006).

\subsection{Explanatory variables on the individual level}

First, we constructed the explanatory variable for the respondent's partnership status. As for relationship dissolution, the data only allow us to take into account a divorce or 
separation after a formal marriage. Respondents indicating they are separated but still legally married are regarded the same way as divorced respondents. We distinguish between six categories: 1) in first marriage, 2) never married, cohabiting with a partner, 3) never married, single (this means no partner in the same household) 4) divorced (or separated), cohabiting with a partner (including both remarriage and unmarried cohabitation), 5) divorced, single, and 6) widowed.

Employed mothers have different child care needs than mothers who do not go out to work. We therefore included a variable in the analyses that indicates the employment status of mothers. It refers to whether or not the respondent was in paid work the last seven days before the interview, not necessarily as the main activity. Respondents in paid work were asked how many hours a week they normally work in their main job, regardless of their basic or contracted hours, including paid or unpaid overtime. This information is included in the model that is estimated for mothers in paid work only (see model III in the results section for the rationale for doing this).

The probability that grandparents provide the main source of child care for respondent's children heavily depends on the number and gender of grandparents still alive. As ESS2 only provides this information for the respondent's own parents, we included a variable 'parents alive' with four categories in the analyses: 1) both parents are still alive, 2) only the mother is still alive, 3) only the father is still alive, and 4) own parents are not alive anymore. Even if respondents in this last category do not have parents to provide child care to their children, they were still included in the analyses because the parents of the partner or ex-partner of the respondent may still be alive. Unfortunately, ESS does not provide this information on the parents of (ex-)partner of the respondent. Also information on the age, labour market participation and health status of grandparents is missing.

From the household grid, we know whether respondents are cohabiting with their parents or parents-in-law. We add a dummy to our models indicating whether or not at least one parent or parent-in-law is living in the same household as the respondent. The indicator for a respondent's family norms consists of a principal component score, based on three items described earlier (see 4.4). A higher score means that the respondent holds more conservative attitudes towards gender and family. Other variables controlled for are the respondent's age, the number of children up to 12 years living in the same household, and the respondent's level of education. ESS2 uses the International Standard Classification for Education (Unesco 2006), but for this paper we reduced the number of categories for the highest level of education respondents achieved to three: 'low' level of education if no qualification or degrees up to lower secondary school, 'medium' for upper or post secondary (non-tertiary) schooling, and 'high' for tertiary education. The low level of education is the reference category. Table 3 lists the descriptive statistics of the individual level variables used in the analysis. 
Table 3: Descriptives of the dependent and independent variables on the individual level

\begin{tabular}{|c|c|c|c|c|c|c|}
\hline & $\mathbf{N}$ & $\%$ & Mean & SD & Min & Max \\
\hline \multicolumn{7}{|l|}{ Grandparents as main source of child care } \\
\hline Yes & 1234 & 43.8 & & & & \\
\hline No & 1581 & 56.2 & & & & \\
\hline \multicolumn{7}{|l|}{ Employment } \\
\hline In paid work & 2082 & 74.0 & & & & \\
\hline Not in paid work & 733 & 26.0 & & & & \\
\hline If in paid work: hours working per week & & & 34.7 & 12.6 & 0.0 & 90.0 \\
\hline \multicolumn{7}{|l|}{ Partner status } \\
\hline In first marriage & 1926 & 68.4 & & & & \\
\hline Never married, cohabiting with partner & 267 & 9.5 & & & & \\
\hline Never married, single & 175 & 6.2 & & & & \\
\hline Divorced, cohabiting with partner & 196 & 7.0 & & & & \\
\hline Divorced, single & 226 & 8.0 & & & & \\
\hline Widowed & 25 & 0.9 & & & & \\
\hline \multicolumn{7}{|l|}{ Parents still alive } \\
\hline Both parents alive & 1980 & 70.3 & & & & \\
\hline Only mother alive & 545 & 19.4 & & & & \\
\hline Only father alive & 153 & 5.4 & & & & \\
\hline No parents alive & 137 & 4.9 & & & & \\
\hline \multicolumn{7}{|l|}{ Level of education } \\
\hline Low & 616 & 21.9 & & & & \\
\hline Medium & 1340 & 47.6 & & & & \\
\hline High & 859 & 30.5 & & & & \\
\hline Age & & & 35.2 & 6.1 & 20.0 & 54.0 \\
\hline Number of children $<13$ in household & & & 1.6 & 0.7 & 1.0 & 7.0 \\
\hline \multicolumn{7}{|l|}{ Parents (in law) in the same household } \\
\hline Yes & 2619 & 93.0 & & & & \\
\hline No & 196 & 7.0 & & & & \\
\hline Conservative family norms (component scores) & & & -0.4 & 0.9 & -2.1 & 2.4 \\
\hline
\end{tabular}

\section{Results}

Table 4 shows results of three multilevel models, all including random intercepts for the country and the NUTS 1 regional level. Model I also includes the individual-level covariates, except for two individual-level indicators that may reflect regional heterogeneity in family norms and practices: living together with parents or parents-inlaw and mother's own attitudes towards the role of men, women and the family. These 
two indicators are added in model II, as well as the coverage rate of formal child care in the country and the indicators on the regional level. Model III only includes European mothers who are in paid work and takes into account their working hours.

As to the individual level covariates in model I, on average across Europe, the age of mothers is associated with a lower probability that grandparents serve as the main child care providers. As expected, this probability also descends with the number of children in the household, presumably because caring for more children implies a heavier task for grandparents. Having grandparents providing the main source of child care for children is significantly less common among mothers in paid work compared to mothers without a job. Mothers without a job probably do not use much of the formal services because they do not need child care on a regular basis. Hence, the times they do need child care, grandparents serve more often as the main providers. The level of education of mothers is also related to their child care use: when compared to mothers with a low level of education, highly educated women are less likely to mainly make use of grandparents as main child care providers, while women with mid-range education are more likely to do so. As to the partnership status, mothers in their first marriage are the most likely to use grandparents as the main source of child care. For never married mothers who are cohabiting with a partner and for divorced mothers without a partner in the household, the probability of relying on grandparents is significantly lower. Also, the probability to have grandparents as the main source of child care is the highest if both maternal grandparents are still alive. However, this probability is not significantly lower if only the mother of the respondent is still alive, also pointing to the gendered nature of providing grandchild care. When only the father is still alive or when both parents of the respondents have deceased, in contrast, the probability that a mother's children are mainly cared for by grandparents is significantly lower.

Model I includes random intercepts on the level of countries and on the level of NUTS 1 regions. Map 5 presents the variation in random effects between different NUTS 1 regions. To this end, Empirical Bayes Estimates (Snijders and Bosker 1999) of NUTS 1 random effects were summated with these of their respective countries. Mothers in Italy, Greece, the south and the center of Spain and the most western regions of Austria and Hungary belong to those who are the most likely to mainly rely on grandparents as child care providers. In Sweden, Denmark, Iceland and France, the probabilities that grandparents provide the main type of child care belong to the lowest range. A substantial share of the variation in the reliance on grandparents as the main providers of child care is situated on the country level, but there are also major intranational regional differences, especially in Spain, Italy, Greece, Germany, Austria, Hungary and Sweden. 
Table 4: Multilevel logistic regression models of the use of grandparents as the main source of child care by European mothers aged 20-54

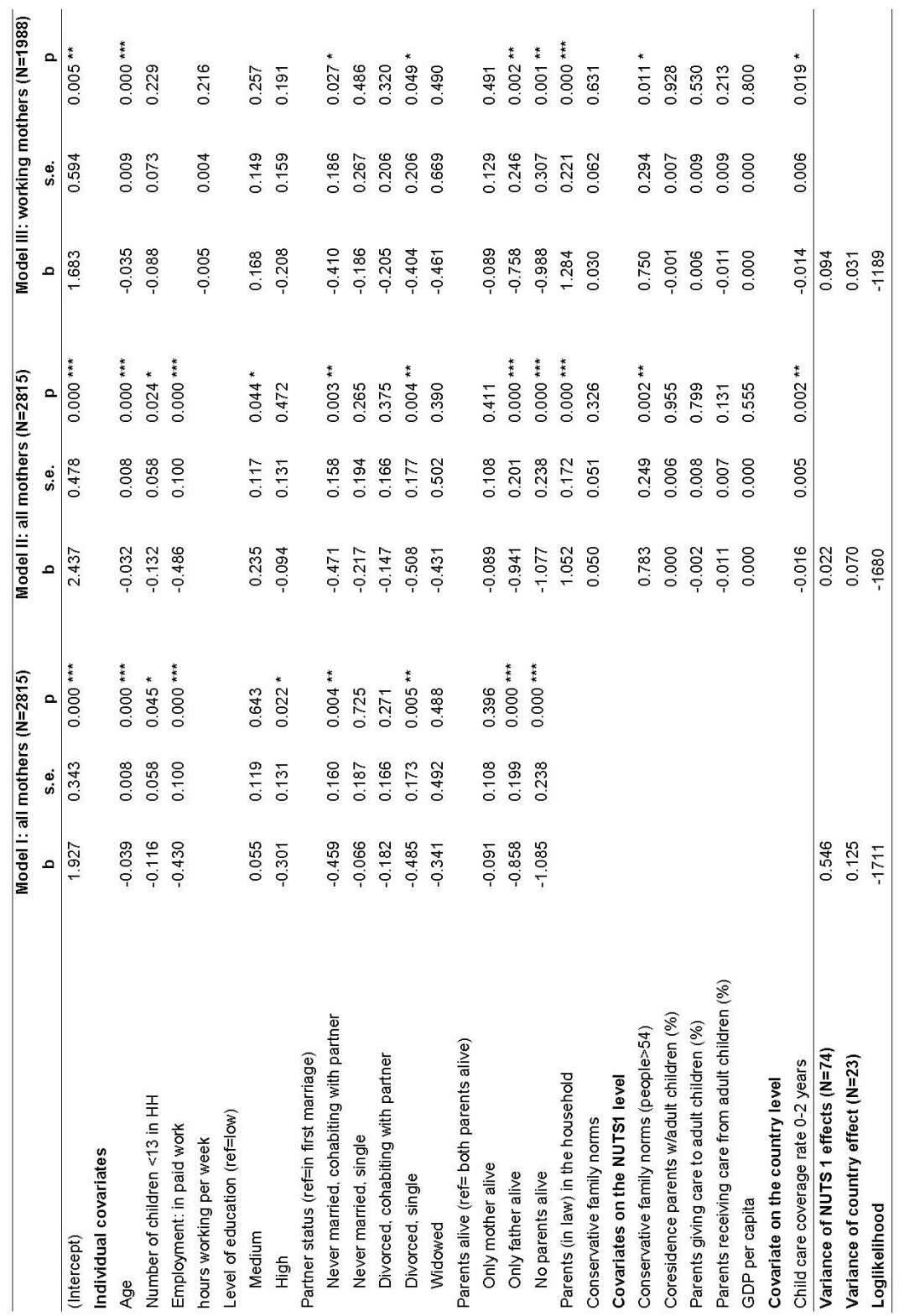


Map 5: $\quad$ Estimates of NUTS 1-level random effects in model I

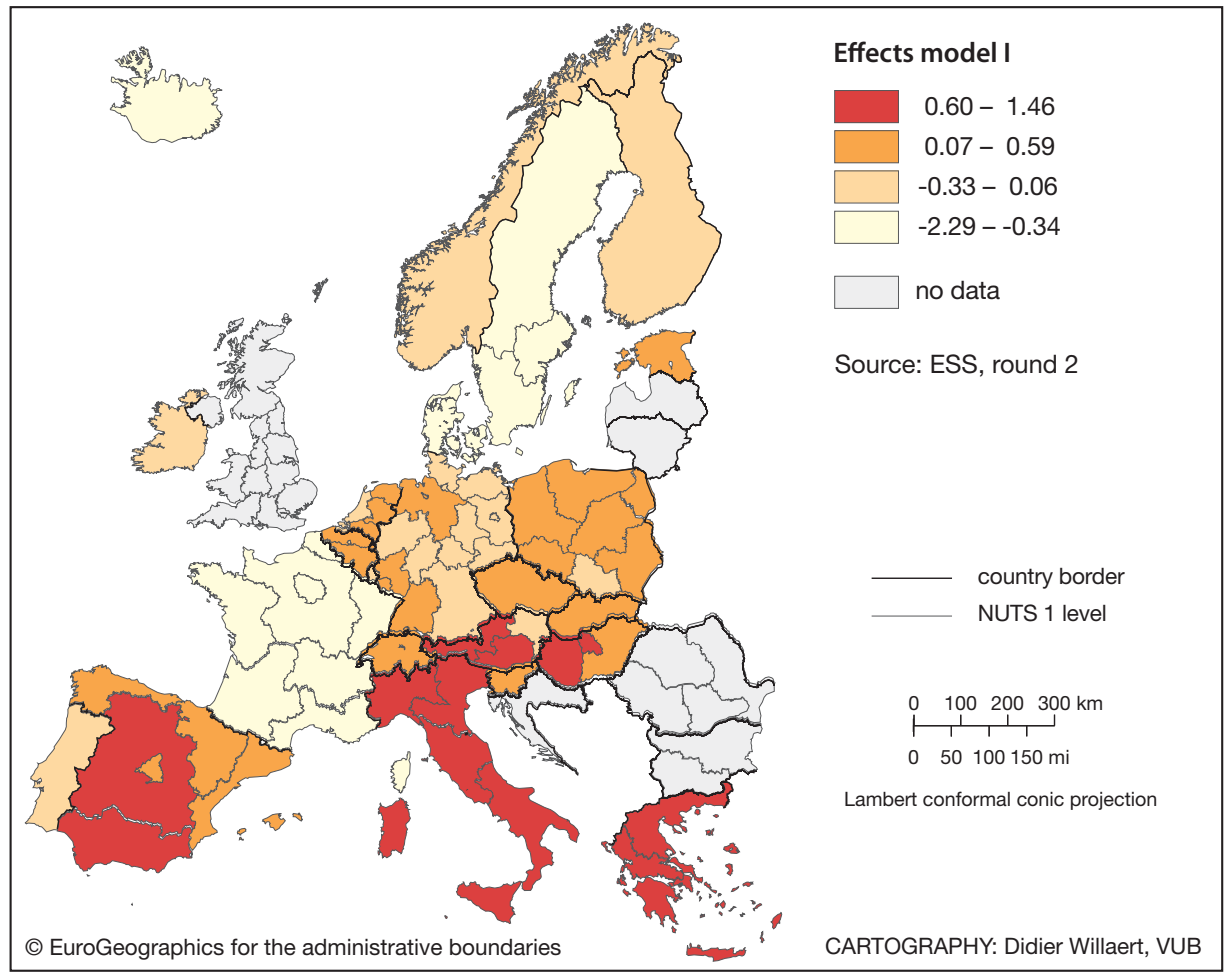

In model II we added our indicators on the country and the regional level, as well as the attitude of the mother towards family norms and whether or not she is living under the same roof with her parents or parents-in-law. The effects of the individual level variables still point in the same direction as before. Moreover, results show that, unsurprisingly, having at least one grandparent living in the household significantly increases the probability that a child is mainly cared for by grandparents when the parents themselves are unable to do so. Mothers' own individual attitudes towards family and gender do not seem to make an impact upon the likelihood of relying on grandparents for child care provision.

A key result is that, while the attitudes towards family and gender of a mother herself do not have a significant impact on her use of child care, the attitudes prevailing in her region of residence do. The more conservative the normative climate, the more 
inclined mothers are to use grandparents as the main source of child care for their children. So, it is the regional family culture rather than the attitude individually held that seems to matter for child care practices. The regional indicators of family practices, the percentage of older parents living with adult children, the percentage of parents giving care to and the percentage receiving care form adult children, do not have a statistically significant influence. Also the gross domestic product of the region has no impact on the choice of grandparents over other types of child care. As expected, the availability of formal child care provisions in the country of residence does significantly affect the probability that mothers mainly rely on grandparents for child care: the higher the formal child care coverage rate, the less likely that grandparents serve as the main source of child care.

The labour market participation of mothers is surely connected to their use of child care, and patterns of female and maternal employment vary widely across Europe. As an extra test for the robustness of the effect of regional family norms, we only take into account mothers aged 20-54 in paid work in regression model III. In addition, one extra variable is introduced: the hours normally worked per week. The effects of the aggregate level variables hardly change: in countries with higher formal child care coverage rates and in more progressive regions, also working mothers are less inclined to mainly rely on grandparents for child care. The working hours of these mothers do not play a significant role in their choice for grandparents rather than other types of child care.

\section{Conclusions}

Child care and regional differences in practices and attitudes towards family life are both important components of European policies aimed at boosting the labour market participation of women. The importance of child care is widely acknowledged, the importance of normative climates is not. Yet, some regions hold a considerable resistance to the idea that also a mother with young children should go out to work. Social policies aiming to encourage the labour market participation of young mothers would benefit from taking this into account.

As the labour market participation of women is increasing, so is the demand for child care. As to informal child care, grandparents are by far the most important child care providers throughout Europe. In this article, we investigated the extent to which European mothers use grandparents as the main source of child care for their children. This implies that mothers rely on the child's grandparents more intensely than on other, mainly formal alternatives of child care. We were particularly interested whether 
mothers' child care choices are related to the family practices and norms prevailing in their region of residence.

Europe has been and continues to be characterized by a great international diversity of attitudes as well as practices in family life. The European picture cannot be summarized by simply making the distinction between familialistic Southern Europe and individualistic Northern Europe. There are differences within these big groups of countries, and not all countries behave like one would expect based on this North-South scheme. In addition, there exists essential heterogeneity within the borders of these countries. In this paper, we attempted to take this regional heterogeneity in family life, across and within countries, into account. Using the second round of the European Social Survey, we scored subnational regions of Northern, Southern, Western as well as Eastern Europe on a number of actual family practices as well as on family norms. More specifically, we constructed an indicator for conservative norms about gender roles in the family, estimated the percentage of older parents co-residing with children, the percentage of older parents providing care or support with housework to adult children outside the household, and the percentage of older parents receiving care or support from children outside the household.

Broadly seen, more conservative family norms were mainly found in Southern and Eastern European regions, where coresidence between older parents and children is also clearly more common than in other parts of Europe. Everyday exchange of support between parents and children living in separate households is most common in Eastern European regions and least common in Southern European regions. In Southern Europe, it seems that coresidence is the typical way of support exchange between older parents and adult children in most regions. When parents and children do not live together, markedly less support appears to be exchanged when compared to most Northern European regions, where coresidence between parents and children is not common. In Central and Eastern European regions, a substantive share of older parents and children do live together, but also when this is not the case, many of them exchange support in housework and care. This very broad summarization does, however, neglect intracountry differences in the various aspects of family practices and norms, as these are clearly present.

The regional indicators of family practices and norms were then used in a multilevel analysis to test whether or not they can help to explain European mothers' use of grandchild care. Results show that in Italy, Greece and some parts of Spain, Austria and Hungary, the probability that mothers mainly rely on grandparents to provide child care for their children is highest. In regions in Sweden, Denmark and France, this probability is lowest. A substantial share of the variation in the reliance on grandparents as the main providers of child care is situated on the country level, even though there are also major intra-national regional differences. In line with other 
research, our analyses show that the availability of formal child care provisions is an important contextual factor: the higher the formal child care coverage rate in a country, the smaller the probability that mothers will count on grandparents as the main source of child care for their children.

Even after controlling for the supply of formal child care, our results showed that European mothers' child care strategies are also influenced by the normative climate of the region in which they live. While the attitudes towards family and gender held individually by the mothers themselves have no significant impact, the attitudes prevailing in the region of residence do have an impact on the likelihood of mainly relying on grandparents for child care. Mothers in more conservative regions are clearly more inclined to use grandparents as the main source of child care for their children instead of formal alternatives. These preferences can be important in making national and European policies to sustain families and encourage the labour market participation of young mothers.

A methodological limitation of this study is the low reliability of the measures of family norms and practices in some regions. For countries that are divided in a large number of NUTS 1 regions, like Germany, the number of ESS2 respondents per region becomes very small. This reduced reliability introduces noise in the analyses, and this noise implies that our estimates of association between the regional indicators and the use of grandparents as main child care providers should be considered as conservative ones. Therefore we feel confident in concluding that European patterns of child care use are not only subject to structural factors as the supply of formal care provisions for children. Preferences and attitudes prevalent in the regions in which young parents live form an important part of the picture too.

\section{Acknowledgements}

The research leading to these results has received funding from the European Union's Seventh Framework Programme [FP7/2007-2011]) under grant agreement $n^{\circ} 217523$ for the project MULTILINKS (How demographic changes shape intergenerational solidarity, well-being, and social integration: A multilinks framework). We also thank the two anonymous reviewers as well as guest editor Pearl Dykstra for numerous helpful suggestions. 


\section{References}

Albertini, M., Kohli, M., and Vogel, C. (2007). Intergenerational transfers of time and money in European families: Common patterns - different regimes? Journal of European Social Policy 17(4): 319-334. doi:10.1177/0958928707081068.

Arpino, B., Pronzato, C., and Tavares, L. (2010). All in the family: Informal child care and mothers' labour market participation. Essex: Institute for Social and Economic Research (ISER Working Paper Series; 2010-24).

Attias-Donfut, C., Ogg, J., and Wolff, F.-C. (2005a). Family Support. In: BörschSupan, A. (ed.). Health, Ageing and Retirement in Europe. First results from the Survey of Health, Ageing and Retirement in Europe. Mannheim: Mannheim Research Institute for the Economics of Aging: 171-178.

Attias-Donfut, C., Ogg, J., and Wolff, F.-C. (2005b). European patterns of intergenerational financial and time transfers. European Journal of Ageing 2(3): 161-173. doi:10.1007/s10433-005-0008-7.

Bettio, F. and Plantenga, J. (2004). Comparing care regimes in Europe. Feminist Economics 10(1): 85-113.doi:10.1080/1354570042000198245.

Beugelsdijk, S., Van Schaik, T., and Arts, W. (2006). Toward a unified Europe? Explaining regional differences in value patterns by economic development, cultural heritage and historical shocks. Regional Studies 40(3): 317-327. doi:10.1080/00343400600631590.

Brandis, J. (2003). Grandparents as child care givers for working mothers. A literature review in Spain and other advanced societies. Madrid: Universidad Carlos III de Madrid.

Brandt, M., Haberkern, K., and Szydlik, M. (2009). Intergenerational help and care in Europe. European Sociological Review 25(5): 585-601. doi:10.1093/esr/jcn076.

Croda, E. and Gonzalez-Chapela, J. (2005). How do European Older Adults Use Their Time? In: Börsch-Supan, A. (ed.). Health, Ageing and Retirement in Europe. First results from the Survey of Health, Ageing and Retirement in Europe. Mannheim: Mannheim Research Institute for the Economics of Aging: 265-271.

Daatland, S.O. and Herlofson, K. (2003). 'Lost solidarity' or 'changed solidarity': A comparative European view of normative family solidarity. Ageing and Society 23: 537-560. doi:10.1017/S0144686X03001272. 
Danielsbacka, M., Tanskanen, A.O., Jokela, M., and Rotkirch, A. (2011). Grandparental child care in Europe: Evidence for preferential investment in more certain kin. Evolutionary Psychology 9(1): 3-24.

Dunne, E.G. and Kettler, L.J. (2007). Grandparents raising grandchildren in Australia: Exploring psychological health and grandparents' experience of providing kinship care. International Journal of Social Welfare 17(4): 333-345. doi:10.1111/j.1468-2397.2007.00529.x.

Duranton, G., Rodríguez-Pose, A., and Sandall, R. (2007). Family types and the persistence of regional disparities in Europe. Bruges: College of Europe (Bruges European Economic Research Papers; 10).

Dykstra, P.A. (2012). Families: In alle staten? Rede uitgesproken bij de openbare aanvaarding van het ambt van hoogleraar Empirische Sociologie aan de Erasmus Universiteit Rotterdam op 27 januari 2012 [electronic resource]. Rotterdam: Erasmus Universiteit Rotterdam. http://www.eur.nl/fileadmin/ASSETS/fsw/ nieuws/Oratie_Pearl_Dykstra_-_Families_in_alle_staten.pdf.

Dykstra, P.A. and Fokkema, T. (2011). Relationships between parents and their adult children: A West European typology of late-life families. Ageing and Society 31(4): 545-569. doi:10.1017/S0144686X10001108.

Erbert, L.A. and Alemán, M.W. (2008). Taking the grand out of grandparent: Dialectical tensions in grandparent perceptions of surrogate parenting. Journal of Social and Personal Relationships 25(4): 671-695.doi:10.1177/0265407 508093785 .

ESS Central Coordinating Team (2010). ESS 2 - 2004 Summary and deviations [electronic resource]. Norwegian Social Science Data Services. http://ess.nsd.uib.no/ess/round2/deviations.html.

European Commission (2005). Green Paper 'Confronting demographic change: A new solidarity between the generations'. Luxembourg: Office for Official Publications of the European Communities.

European Monitoring Centre on Change (2006). Sector Futures. Child care services sector. Dublin: European Foundation for the Improvement of Living and Working Conditions.

Eurostat (2010). Statistics [electronic resource]. Luxembourg: European Commission. http://epp.eurostat.ec.europa.eu/portal/page/portal/statistics/themes. 
Fergusson, E., Maughan, B., and Golding, J. (2008). Which children receive grandparental care and what effect does it have? Journal of Child Psychology and Psychiatry 49(2): 161-169. doi:10.1111/j.1469-7610.2007.01840.x.

Fokkema, T., Ter Bekke, S., and Dykstra, P.A. (2008). Solidarity between parents and their adult children in Europe. Den Haag: Netherlands Interdisciplinary Demographic Institute (NIDI reports; 76).

Fuller-Thomson, E. and Minkler, M. (2001). American Grandparents Providing Extensive Child Care to Their Grandchildren: Prevalence and Profile. The Gerontologist 41(2): 201-209. doi:10.1093/geront/41.2.201.

Georgas, J., Mylonas, K., Gari, A., and Panagiotopoulou, P. (2004). Families and values in Europe. In: Arts, W. and Halman, L. (eds.). European Values at the Turn of the Millennium. Leiden: Brill: 167-202.

Ghysels, J. (2011). The provision of informal child care by European grandparents: Constraints versus selective preferences. Antwerp: Herman Deleeck Centre for Social Policy (CSB Working Papers; 11/08).

Gray, A. (2005). The changing availability of grandparents as carers and its implications for child care policy in the UK. Journal of Social Policy 34(4): 557577. doi:10.1017/S0047279405009153.

Guzman, L. (2004). Grandma and Grandpa Taking Care of the Kids: Patterns of Involvement. Washington D.C.: Child Trends (Child Trend Research Briefs; 2004-17).

Hank, K. (2007). Proximity and contacts between older parents and their children: A European comparison. Journal of Marriage and Family 69(1): 157-173. doi:10.1111/j.1741-3737.2006.00351.x.

Hank, K. and Buber, I. (2009). Grandparents caring for their grandchildren: Findings from the 2004 survey of health, ageing and retirement in Europe. Journal of Family Issues 30(1): 53-73. doi:10.1177/0192513X08322627.

Heady, P. and Kohli, M. (2010). Introduction: Towards a political economy of kinship and welfare. In: Heady, P. and Kohli, M. (eds.). Family, Kinship and state in contemporary. Volume 3. Perspectives on theory and policy. Frankfurt: Campus: $15-30$.

High Level Group chaired by WimKok (2004). Facing the Challenge: The Lisbon Strategy for Growth and Employment. Luxembourg: Office for Official Publications of the European Communities. 
Igel, C., Brandt, M., Haberkern, K., and Szydlik, M. (2009). Specialization between family and state. Intergenerational time transfers in Western Europe. Journal of Comparative Family Studies 40(2): 203-226.

Igel, C. and Szydlik, M. (2011). Grandchild care and welfare state arrangements in Europe. Journal of European Social Policy 21(3): 210-224. doi:10.1177/ 0958928711401766 .

Immervoll, H. and Barber, D. (2006). Can Parents Afford to Work? Child care Costs, Tax-Benefit Policies and Work Incentives. Bonn: The Institute for the Study of Labor IZA (IZA Discussion Papers; 1932).

Inglehart, R. and Baker, W.E. (2000). Modernization, Cultural Change, and the Persistence of Traditional Values. American Sociological Review 65(1): 19-51. doi: $10.2307 / 2657288$.

Inglot, T. (2008). Welfare States in East Central Europe: 1919 -2004. Cambridge: Cambridge University Press. doi:10.1017/CBO9780511510175.

Kalmijn, M. and Saraceno, C. (2008). A comparative perspective on intergenerational support. Responsiveness to parental needs in individualistic and familialistic countries. European Societies 10(3): 479-508. doi:10.1080/14616690701744364.

Kalmijn, M. and Uunk, W. (2007). Regional value differences in Europe and the social consequences of divorce: A test of the stigmatization hypothesis. Social Science Research 36(2): 447-468. doi:10.1016/j.ssresearch.2006.06.001.

Keck, W., Hessel, P., and Saraceno, C. (2009). Multilinks Database on Intergenerational Policy Indictors. Methodological Report. Berlin: Social Science Research Center Berlin.

Knijn, T.C.M. and Liefbroer, A.C. (2006). More kin than kind: Instrumental support in families. In: Dijkstra, P.A., Kalmijn, M., Knijn, T.C.M., Kompter, A.E., Liefbroer, A.C., and Mulder, C.H. (eds.). Family solidarity in the Netherlands. Amsterdam: Dutch University Press: 89-105.

Kocourková, J. (2002). Leave arrangements and child care services in Central Europe: Policies and practices before and after the transition. Community, Work and Family 5(3): 301-318. doi:10.1080/1366880022000041793.

Kohli, M. and Albertini, M. (2007). The Generational Contract in the Family. Explaining Regime Differences in Financial Transfers from Parents to Children in Europe. Barcelona: Universitat Pompeu Fabra (Demosoc Working Papers; 2007-24). 
Kohli, M. and Heady, P. (2010). Conclusion: Implications for policy. In: Heady, P. and Kohli, M. (eds.). Family, Kinship and state in contemporary. Volume 3. Perspectives on theory and policy. Frankfurt: Campus: 395-410.

Kohli, M., Künemund, H., and Lüdicke, J. (2005). Family Structure, Proximity and Contact. In: Börsch-Supan, A. (ed.). Health, Ageing and Retirement in Europe. First results from the Survey of Health, Ageing and Retirement in Europe. Mannheim: Mannheim Research Institute for the Economics of Aging: 164-170.

Leder, S., Nicholson Grinstead, L., and Torres, E. (2007). Grandparents raising grandchildren. Stressors, social support, and health outcomes. Journal of Family Nursing 13(3): 333-352. doi:10.1177/1074840707303841.

Lewis, J., Campbell, M., and Huerta, C. (2008). Patterns of paid and unpaid work in Western Europe: Gender, commodification, preferences and the implications for policy. Journal of European Social Policy 18(1): 21-37. doi:10.1177/ 0958928707084450 .

Micheli, G.M. (2012). Two strong families in Southern Europe? Re-examining the geography of kinship regimes stemming from the reciprocity mechanisms between generations. European Journal of Population 28(1): 17-38. doi:10.1007/s10680-011-9245-y.

OECD (2008a). OECD Family Database. Public spending on child care and early education [electronic resource]. Paris: OECD - Social Policy Division Directorate of Employment, Labour and Social Affairs. http://www.oecd.org/els/ social/family/database.

OECD (2008b). OECD Family Database. Enrolment in day-care and pre-schools [electronic resource]. Paris: OECD - Social Policy Division - Directorate of Employment, Labour and Social Affairs. http://www.oecd.org/els/social/ family/database.

Plantenga, J. and Remery, C. (2009). The provision of child care services. A comparative review of 30 European countries. Luxembourg: Office for Official Publications of the European Communities.

Reher, D. (1998). Family ties in Western Europe: Persistent contrasts. Population and Development Review 24(2): 203-234. doi:10.2307/2807972.

Robila, M. (2004). Families in Eastern Europe: Context, trends and variations. In: Robila, M. (ed.). Families in Eastern Europe. Contemporary Perspectives in Family Research, Vol. 5. Amsterdam: Elsevier: 1-14. 
Różańska-Putek, J., Jappens, M., Willaert, D., and Van Bavel, J. (2009). Recoding the Regions of the European Social Survey into the NUTS 1 Regional Classification. Illustration: Regional indicators of intergenerational solidarity. Brussels: Vrije Universiteit Brussel (Interface Demography Working Papers; 2009-6).

Sannen, L. and Hedebouw, G. (2002). Grootouders of andere familieleden en kinderopvang. Betrokkenheid, motieven, evaluatie en toekomstige bereidheid. Leuven: Hoger instituut voor de arbeid.

Santarelli, E. and Cottone, F. (2009). Leaving home, family support and intergenerational ties in Italy: Some regional differences. Demographic Research 21(1): 1-22. doi:10.4054/DemRes.2009.21.1.

Saraceno, C. (2011). Child care needs and child care policies: A multidimensional issue. Current Sociology 59(1): 78-96. doi:10.1177/0011392110385971.

Schenk, N., Dykstra P., and Maas, I. (2009). De invloed van Europese verzorgingsstaten op financiële overdrachten binnen families. Een benadering op microniveau. Mens en Maatschappij 84: 329-355.

Settles, B.H., Zhao, J., Doneker Mancini, K., Rich, A., Pierre, S., and Oduor, A. (2009). Grandparents caring for their grandchildren: Emerging roles and exchanges in global perspectives. Journal of Comparative Family Studies 40(5): 827-848.

Smith Koslowski, A. (2009). Grandparents and the care of their grandchildren. In: Stillwell, J., Coast, E., and Keele, D. (eds.). Fertility, Living Arrangements and Care: Understanding Population Trends and Processes. Dordrecht: Springer: 171-190. doi:10.1007/978-1-4020-9682-2 9.

Szelewa, D. and Polakowski, M.P. (2008). Who cares? Changing patterns of child care in Central and Eastern Europe. Journal of European Social Policy 18(2): 115131. doi:10.1177/0958928707087589.

Tobío, C., Tomás, S.A., Gómez, V., and Paloma, T.M. (2010). Caring for others: A challenge for the 21st century. Barcelona: Fundación "La Caixa" (Social Studies Collection; 28).

Todd, E. (1990). L'invention de l'Europe. Paris: Seuil.

Tomassini, C., Kalogirou, S., Grundy, E., Fokkema, T., Martikainen, P., Broese van Groenou, M., and Karisto, A. (2004). Contacts between elderly parents and their children in four European countries: Current patterns and future prospects. European Journal of Ageing 1(1): 54-63. doi:10.1007/s10433-004-0003-4. 
Unesco (2006). International Standard Classification of Education ISCED 1997. Montreal: Unesco Institute for Statistics.

Van Bavel, J. (2004). Beroepsarbeid van vrouwen en de daling van de vruchtbaarheid in het Westen, 1850-2000. Is er een oorzakelijk verband? Bevolking en Gezin 33(1): 61-90.

Vandell, D.L., McCartney, K., Owen, M.T., Booth, C., and Clarke-Stewart, A. (2003). Variations in child care by grandparents during the first three years. Journal of Marriage and Family 65(2): 375-381. doi:10.1111/j.1741-3737.2003.00375.x.

Viazzo, P.P. (2003). What's so special about the Mediterranean? Thirty years of research on household and family in Italy. Continuity and Change 18(1): 111137. doi:10.1017/S0268416003004442.

Voicu, M. (2004). Work and family life in Europe: Value patterns and policy making. In: Arts, W. and Halman, L. (eds.). European Values at the Turn of the Millennium. Leiden: Brill: 231-254.

Wheelock, J. and Jones, K. (2002). 'Grandparents are the next best thing': Informal child care for working parents in urban Britain. Journal of Social Policy 31(3): 441-463. doi:10.1017/S0047279402006657.

Wolff, F.-C. and Attias-Donfut, C. (2007). Les comportements de transferts intergénérationnels en Europe. Economie et Statistique 403(403-404): 117-141. doi:10.3406/estat.2007.7091.

Woodhouse, G., Yang, M., Goldstein, H., and Rasbash, J. (1996). Adjusting for measurement error in multilevel analysis. Journal of the Royal Statistical Society, Series A (Statistics in Society) 159(2): 201-212. doi:10.2307/2983168. 